\title{
Design of composite materials for clothes
}

\author{
Sergey Koksharov ${ }^{1}$, Nadezhda Kornilova ${ }^{2 *}$, and Yulia Shammut ${ }^{2}$ \\ ${ }^{1}$ G.A. Krestov Institute of Solution Chemistry of the Russian Academy of Sciences, 153045, Ivanovo, \\ Akademicheskaya st, 1, Russia \\ ${ }^{2}$ Ivanovo State Polytechnic University, 153000, Ivanovo, Sheremetevsky ave., 21, Russia
}

\begin{abstract}
Transition to digital models of garments is the first step in digitization of the light industry. Adequate digital models can be obtained by using precise parameters of stress-strain properties of a fabric and other materials. The study has revealed regression dependences of the stiffness index of the polymer - fibre composite on the stiffness of the suit fabric and the combination of fusible interlining parameters. The obtained equations can be used to design composite materials of the required stiffness, depending on the form of clothing being created
\end{abstract}

\section{Introduction}

The first step in the digital transformation of apparel industry is to replace physical samples with virtual garments or digital twins - an accurate digital version of the garment that designers can manipulate exactly as they would a physical version. These digital garment twins should be produced in a fast and scalable way, removing the need to wait for a physical garment to make design decisions. From design to fitting and adjustments, all the way through to sales in an online shop, using a digital garment reduces the time to market from almost a year to merely days [1].

Virtual garment design and simulation involves a combination of a large range of techniques, involving mechanical simulation, collision detection, and others. Article [2] provides an overview of the evolution of these techniques made in the last decade to bring virtual garments to the reach of computer applications not only aimed at graphics, but also at CAD techniques for the garment industry. If cloth simulations could be improved to the point that they could generate realistic cloth motion in real-time, they would find uses in many aspects of fashion design and manufacturing [3 - 5].

When applying physical simulation, CAD producers have to look for a compromise between simulation time and resource-intensity and, on the other hand, between the accuracy of material simulation and closeness to the garment fit [4]. Flexibility of the structure, compound weave, anisotropy, drapability and absence of static position make simulation of textile materials much more complicated than the simulation traditionally used in machine building, architecture and other fields of industry.

A separate problem is taking into account properties of bonded zones of garment parts whose stress-strain properties may be different from those of the neighboring (non-bonded) zones by dozens of times [6].

\footnotetext{
*Corresponding author: nkorn@mail.ru
} 
As shown in $[7,8]$, these sections are a composite, which consists of several layers of textile materials connected by a thermo-fusible adhesive. To obtain it in the sewing industry, prepreg technologies of forming garments using hot-melt adhesive interlining materials are widely used [9]. The properties of the resulting composite are affected by the composition of the hot-melt adhesive polymer, the method of applying it to the textile liner, and the parameters of processes for bonding the layers and subsequent wet-heat treatment of the finished garment $[10-12]$.

The required level of stiffness of the formed composite is determined depending on the shape of the garment and the properties of the shell material. The stiffer the shape of the garment being created and the softer the material of the top, the greater the load the components made of composite material must withstand.

As Fig. 1 shows, one front part is divided into several zones with different levels of required stiffness. By studying some samples of men's jackets of different models, we have established that stiffness parameters of the fabrics in each of the zones depend on the degree of plasticity and silhouette, which is demonstrated in Table 1.

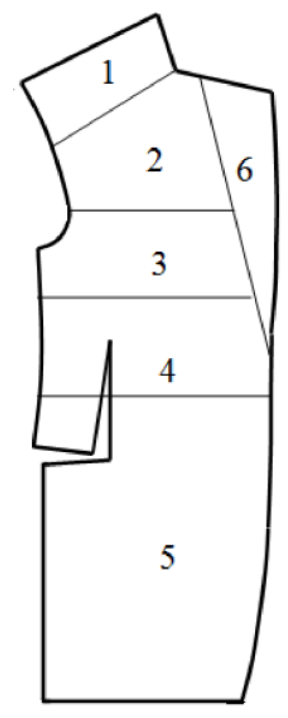

$$
\begin{aligned}
& \text { 1- shoulder; } \\
& 2 \text { - fore top printing; } \\
& 3 \text { - breast foreside; } \\
& \text { 4- breast lower part; } \\
& \text { 5- bottom; } \\
& \text { 6- lapel. }
\end{aligned}
$$

Fig. 1. Different zones of the front of jacket according to a flexural rigidity

The stability of garment shape in different zones of a certain garment part is achieved by using several layers of interlinings - as a rule, at least three different articles with different stiffness and elasticity degrees - fixed to each other and to the base fabric in different ways. Currently, the most widely-used type of fixing is fusing, which employs fusible interlinings $(F I)$. They differ in the structure of the textile carrier (knitted, non-woven or, more rarely, woven fabrics), nature of the adhesive polymer and method of its application $[13,14]$. Presence of a thermoplastic adhesive does not only allow obtaining a strong connection of fabrics but also makes the panel stiff by forming a polymer matrix between the layers, with the matrix properties depending on the polymer type [15]. 
Table 1. Flexural rigidity $\left(E I, 10^{-3} \mathrm{Ncm}^{2}\right)$ of different zones of the front of jacket according to a threedimensional form.

\begin{tabular}{|c|c|c|c|c|c|c|c|c|c|}
\hline \multirow{3}{*}{ Zones } & \multicolumn{9}{|c|}{ Flexural rigidity, $E I, \mathrm{mN} \cdot \mathrm{cm}^{2}$} \\
\hline & \multicolumn{3}{|c|}{$\begin{array}{l}\text { Large three-dimensional } \\
\text { form }\end{array}$} & \multicolumn{3}{|c|}{$\begin{array}{l}\text { Moderate three-dimensional } \\
\text { form }\end{array}$} & \multicolumn{3}{|c|}{$\begin{array}{l}\text { Small three-dimensional } \\
\text { form }\end{array}$} \\
\hline & $\begin{array}{c}\text { soft- } \\
\text { plastic }\end{array}$ & $\begin{array}{l}\text { soft } \\
\text { fixed }\end{array}$ & $\begin{array}{l}\text { frame- } \\
\text { fixed }\end{array}$ & $\begin{array}{c}\text { soft- } \\
\text { plastic }\end{array}$ & $\begin{array}{l}\text { soft } \\
\text { fixed }\end{array}$ & $\begin{array}{l}\text { frame- } \\
\text { fixed }\end{array}$ & $\begin{array}{l}\text { soft- } \\
\text { plastic }\end{array}$ & $\begin{array}{l}\text { soft } \\
\text { fixed }\end{array}$ & $\begin{array}{l}\text { frame- } \\
\text { fixed }\end{array}$ \\
\hline shoulder & $16.5-23.3$ & $24.7-31.5$ & $32.9-39.8$ & $10.9-51.6$ & $17.8-23.3$ & $24.7-30.2$ & $10.9-15.0$ & $16.5-20.5$ & $21.9-26.0$ \\
\hline $\begin{array}{l}\text { fore top } \\
\text { printing }\end{array}$ & $15.0-20.5$ & $21.9-26.1$ & $27.4-32.9$ & $8.2-13.7$ & $15.0-20.6$ & $21.9-27.4$ & $8.2-13.8$ & $15.0-19.2$ & $20.5-24.7$ \\
\hline $\begin{array}{l}\text { breast } \\
\text { foreside }\end{array}$ & $12.3-17.8$ & $19.2-23.3$ & $24.7-27.4$ & $8.2-12.4$ & $13.7-19.2$ & $20.5-24.7$ & $5.5-9.6$ & $10.9-15.0$ & $17.8-21.9$ \\
\hline $\begin{array}{l}\text { breast } \\
\text { lower } \\
\text { part }\end{array}$ & $6.8-10.9$ & $12.3-17.9$ & $19.2-23.3$ & $6.8-10.9$ & $12.3-17.8$ & $12.3-20.6$ & $5.5-9.6$ & \multicolumn{2}{|c|}{$10.9-15.0$} \\
\hline bottom & \multicolumn{9}{|c|}{$4.1-9.6$} \\
\hline lapel & \multicolumn{9}{|c|}{$2.7-10.9$} \\
\hline
\end{tabular}

Normally, the composite material stiffness is varied by changing the fibrous composition of the $F I$, its surface density, type and amount of adhesive polymer. However, the optimal $F I$ types are chosen empirically as there is no literature data about the regularities describing the interconnection between the FI properties and the stiffness of the obtaining composite. This research aims to solve this problem.

\section{Materials and methods}

The objects of study were two types of shell materials for suits (SM1,SM2) and 4 types of fusible interlinings (FI $1 \ldots 4)$.

$S M 1$ - fibrous composition (\%): viscose 55 , wool 35 , polyester 10 ; surface density MS $=240 \pm 3 \mathrm{~g} / \mathrm{m}^{2}$;

$S M 2$ - fibrous composition (\%): viscose 50, polyester 50; $\mathrm{MS}=180 \pm 2 \mathrm{~g} / \mathrm{m}^{2}$.

The properties of fusible interlinings are given in Table 2 .

Table 2. Characteristics of fusible interlinings $(F I)$

\begin{tabular}{|c|c|c|c|c|c|c|}
\hline $\begin{array}{c}\text { Unit } \\
\text { design } \\
\text { ation }\end{array}$ & Manufac-turer & $\begin{array}{c}\text { Vendor } \\
\text { code }\end{array}$ & $\begin{array}{c}\text { Fiber } \\
\text { material, \% }\end{array}$ & $\begin{array}{c}\text { Surface } \\
\text { density, } \\
\text { Ms, g/m2 }\end{array}$ & $\begin{array}{c}\text { Mass fraction } \\
\text { of weft yarns, } \\
G_{W Y} \%\end{array}$ & $\begin{array}{c}\text { Number of glue } \\
\text { dots, } N_{G P}, \\
\text { units / } \mathrm{cm}^{2}\end{array}$ \\
\hline FI1 & Germany & R161G57/090 & $\begin{array}{c}\text { polyester 27, } \\
\text { viscose 73 }\end{array}$ & 58 & 70.5 & 70 \\
\hline FI2 & \multirow{2}{*}{ China } & DIVP 80 & $\begin{array}{c}\text { polyester 30, } \\
\text { viscose 70 }\end{array}$ & 65 & 54.4 & 145 \\
\cline { 1 - 5 } & DI3 & DIVP 65 & $\begin{array}{c}\text { polyester 30, } \\
\text { viscose 70 }\end{array}$ & 80 & 60.8 & 115 \\
\hline FI4 & Russia & $216 / 4$ & $\begin{array}{c}\text { polyester 60, } \\
\text { cotton 40 }\end{array}$ & 75 & 60.8 & 400 \\
\hline
\end{tabular}

Figure 2 demonstrates a typical structural feature of all the studied FI. It consists in the presence of cellulose-containing weft yarn and predominantly lengthwise orientation of the 
warp yarn.

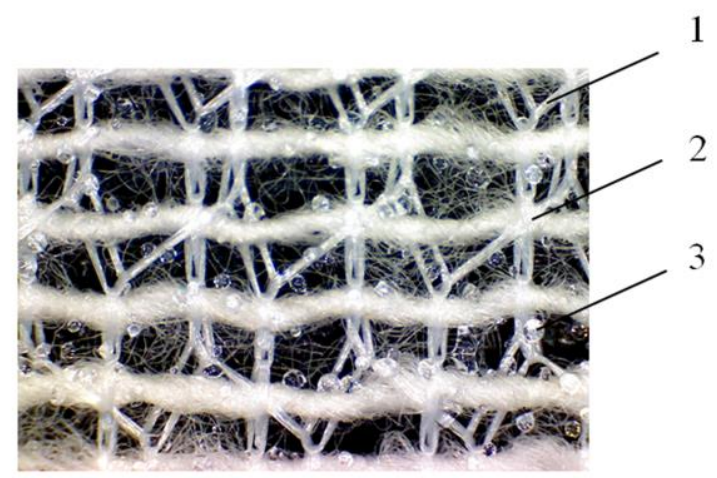

Fig. 2. View of fusible interlinings under the microscope: 1 - ground yarn; 2 - weft yarn; 3 - thermoplastic adhesive fragments (glue points).

The composites studied were obtained on a continuous fusing machine Japsew SR-600 (China) at the temperature of $80^{\circ} \mathrm{C}$ and subsequent steaming at $140{ }^{\circ} \mathrm{C}$ till the moisture content reached $20 \ldots 30 \%$.

The indicator stiffness of textile liner and composites was calculated in accordance with GOST RF 10550-93 using contactless console methodology using the device PT-2 (Fig. 3).

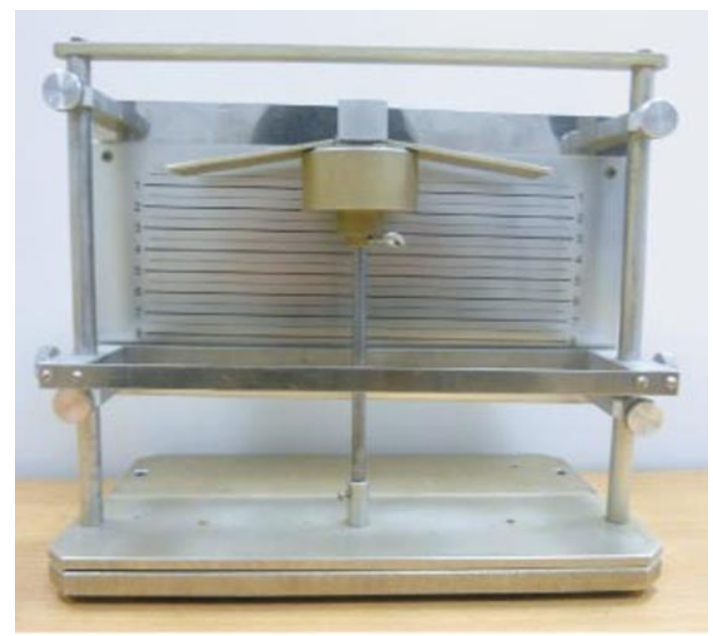

Fig. 3. View of the device PT-2.

The strips of material size of $160 \times 30 \mathrm{~mm}$ were used. They were placed horizontally on the top side of the machine and pressed by the load size of $20 \mathrm{~mm}$ in the middle. After that the sides of anchor were dropped down, the ends of material hanged loose due to gravitational force. After a minute, the amount of overhang of the strips ends was measured. The value of stiffness $E I\left(\mathrm{mN} \cdot \mathrm{cm}^{2}\right)$ was calculated using following formula (1):

$$
E I=\frac{42.046 m}{0.5755 f^{3}-2.411 f^{2}+8.502 f},
$$

where $\mathrm{m}$ is the mass of material strip in grams. 


\section{Results and discussion}

The measurement results are shown in Fig. 4 for the composites with the corresponding type of FI in the structure in comparison with the original indicator level for the suit fabric.

a)

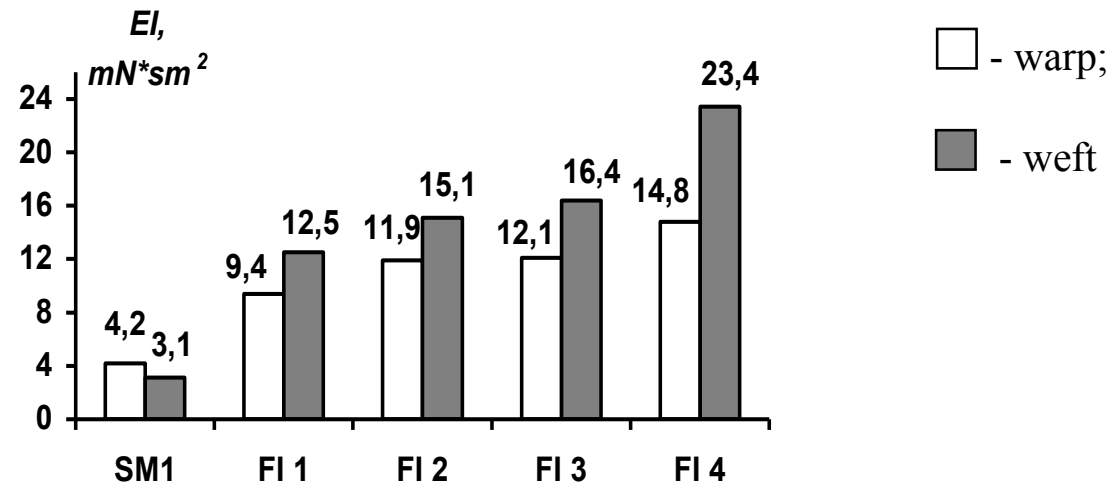

b)

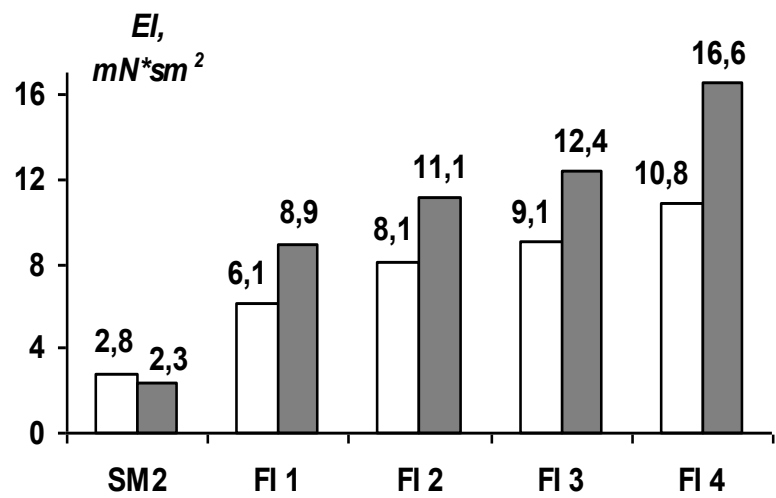

Fig. 4. The indicator stiffness of suit fabrics SM1 (а) и SM2 (б) and the composites with the corresponding type of $F I$

The analysis of the obtained values of composites stiffness $E I^{f p}$ in combination with the $F I$ characteristics given in Table 2 demonstrates an increase in the $E I^{f p}$ as the $M_{S}$ and $N_{G P}$ parameters grow but does not reveal any correlations with any of these individual properties or any their combination. However, if the content of the weft yarn in the textile carrier $\left(G_{W Y}, \%\right)$ is taken into account in the regression analysis, it is possible to reach a satisfactory degree of approximation in the description of the experimental data set. The dependence of the panel warp stiffness $\left(E I_{w a} f p\right)$ or the composite weft stiffness $\left(E I_{w e} f p\right)$ on the stiffness of the shell material and structural characteristics of FI looks as follows:

$$
\begin{aligned}
& E I_{w a}^{f p}=E I_{w a}^{s m}\left(0.027 M_{S}+0.017\left(100-G_{W Y}\right)+0.0025 N_{G P}\right) ; R^{2}=0.9999 \\
& E I_{w e}^{f p}=E I_{w e}^{s m}\left(0.049 M_{S}+0.0086 G_{W Y}+0.0079 N_{G P}\right) ; R^{2}=1.0
\end{aligned}
$$

where $E I_{\text {wa }}{ }^{s m}$ и $E I_{\text {we }}{ }^{s m}$ are the warp and weft stiffness values of the shell material.

The physical meaning of the mathematical model allows us to say that composite stiffness is jointly affected by the stiffness of the original cloth and the interlining. All the equation members have positive values, this indicates that the composite stiffness grows with an increase in any of the input parameters. The weft stiffness in this case becomes higher as 
the content of the weft threads in the interlining grows, whereas the warp stiffness directly depends on the content of $F I$ warp threads.

While analyzing the properties of multi-layered composites, we found a factor of great importance demonstrating the forecasting ability of the obtained mathematical models. For the considered case of applying FI to a knitted cloth of the same type, the resulting composite stiffness value correlates with the value of the additive increment in each of the input values. The $M_{S}$ end $N_{G P}$ values for each of the layers are summed and for $G_{W Y}$ an averaged value is used. For example, for two-layered composites, equations (2) and (3) are transformed in the following way:

$$
\begin{gathered}
E I_{w a}^{f p}=E I_{w a}^{s m}\left(0.027\left(M_{S 1}+M_{S 2}\right)+0.017\left(100-0.5 G_{W Y 1}-0.5 G_{W Y 2}\right)+0.0025\left(N_{G P 1}+N_{G P 2}\right)\right. \\
E I_{w e}^{f p}=E I_{w e}^{s m}\left(0.049\left(M_{S 1}+M_{S 2}\right)+0.0043\left(G_{W Y 1}+G_{W Y 2}\right)+0.0079\left(N_{G P 1}+N_{G P 2}\right)\right.
\end{gathered}
$$

A comparison of the calculated values for all the possible combinations of interlining materials in multi-layered composites that we have studied with the experiment results is given in Table 3. The differences between the corresponding values do not exceed $5 \%$, which indicates that the model can quite satisfactorily predict the stress-strain properties of such composites. The developed approach allows us to effectively select a set of interlining materials for regulating the stiffness of certain zones of a garment in case of changing the model or the shell material. To do that, it is enough to have a set of experimentally determined stiffness values of the shell material with the interlining materials available.

Table 3. The results of modeling the stiffness of multilayer packages

\begin{tabular}{|c|c|c|c|c|}
\hline \multirow{2}{*}{ Package contents } & \multicolumn{2}{|c|}{$E I_{\mathrm{PAC},} \mathrm{mN} \cdot \mathrm{sm}^{2}$} & \multicolumn{2}{c|}{$E I_{\text {эКСп, } \mathrm{mN} \cdot \mathrm{sm}^{2}}$} \\
\cline { 2 - 5 } & warp & weft & warp & weft \\
\hline$S M I+F I 1+F I 2$ & 18.7 & 25.7 & 17.9 & 24.8 \\
$S M I+F I 1+F I 3$ & 19.9 & 27.3 & 19.1 & 26.9 \\
$S M I+F I 1+F I 4$ & 22.3 & 33.6 & 22.4 & 33.9 \\
$S M I+F I 2+F I 3$ & 22 & 30 & 19.2 & 28.8 \\
$S M I+F I 2+F I 4$ & 24.4 & 36.3 & 23.2 & 34.9 \\
$S M I+F I 3+F I 4$ & 25.6 & 37.9 & 23.9 & 36.4 \\
\hline$S M I+F I 1+F I 2+F I 3$ & 29 & 40.7 & 29.9 & 38.7 \\
$S M I+F I 1+F I 2+F I 4$ & 31.4 & 46.9 & 29.9 & 45.7 \\
$S M I+F I 2+F I 3+F I 4$ & 34.6 & 48.5 & 35.7 & 49.6 \\
\hline$S M 2+F I 1+F I 2$ & 12.4 & 18.9 & 13.1 & 19.7 \\
$S M 2+F I 1+F I 3$ & 13.1 & 20.1 & 13.4 & 20.3 \\
$S M 2+F I 1+F I 4$ & 14.7 & 24.7 & 15.1 & 25.0 \\
$S M 2+F I 2+F I 3$ & 14.6 & 22.1 & 15.3 & 22.1 \\
$S M 2+F I 2+F I 4$ & 16.2 & 26.7 & 17.5 & 27.1 \\
$S M 2+F I 3+F I 4$ & 16.9 & 27.9 & 17.4 & 27.3 \\
\hline$S M 2+F I 1+F I 2+F I 3$ & 19.2 & 29.9 & 20.1 & 29.8 \\
$S M 2+F I 1+F I 2+F I 4$ & 20.8 & 34.5 & 22.6 & 34.8 \\
$S M 2+F I 2+F I 3+F I 4$ & 22.9 & 35.7 & 23.9 & 37.4 \\
\hline
\end{tabular}


The obtained data about the elasticity modulus of the original fabric and bonded parts of a garment can be used in the programs for simulating the fit of different types of garments such as coats and suits, shirts and corsets.

\section{Conclusions}

We have determined the ranges of the required stiffness of the men's jacket panel for different zones of the front part depending on the garment silhouette.

We have obtained regression dependences of the stiffness index of the bonded panels of suiting fabric on the stiffness of the shell material and a combination of parameters of the fusible interlining material (surface density, content of weft threads and density of glue points), which allowed us to select interlining materials depending on the required stiffness of a certain garment part.

\section{References}

1. L. Mageean. Which PLM (2018) https://www.whichplm.com/3d-key-complete-digitalapparel-design-process/

2. P. Volino, F. Cordier, N. Magnenat-Thalmann. Computer-Aided Design 37 (6), 593608 (2005)

3. K-J.Choi, H-S.Ko. Computer-Aided Design 37 (6), 585-592 (2005)

4. P. Apeagyei. J. of Fashion marketing and Management 11 (3), 349 - 365 (2007)

5. Y.-J. Liu, D.-L. Zhang and M. Ming-Fai Yuen. Computers in Industry 61, 576-593 (2010)

6. N. Kornilova, S. Koksharov, A. Arbuzova etc. Indian J. of Fibre \& Textile Res. 42, 150-159 (2017)

7. O. Erdem, I. Paul. Woodheap Publishing Series in Textiles 377-420 (2018)

8. Q. Zhang, C-W. Kan. Polymers 10 (11), 1230 (2018)

9. S.A. Koksharov, N.L. Kornilova, J.A. Shammut et al. Key Engineering Materials 816, 219-227 (2019)

10. E.A. Elnashar, P.D. Dubrovski. Autex Res. J. 8 (2), 41-43 (2008)

11. S. Jevsnik, J. Gersak. Fibers \& Textiles in Eastern Europe 12, 1 (45), 47-52 (2004)

12. K. Dapkūnienè, E. Strazdienè. Materials Science (Medžiagotyra). 12 (1), 73 - 78 (2006)

13. L.I. Zhen-Ying. Wool Textile J. 8, 35-39 (2011)

14. S.S. Saleh, E.M. Kamal. J. Basic. Appl. Sci. Res. 2 (10), 9970-9977 (2012)

15. S.A. Koksharov, N.L. Kornilova, S.V. Fedosov. Russian J. of General Chemistry 87 (6), 1428-1438 (2017) 